\title{
Retrospective analysis of Japanese patients with relapse or refractory small-cell lung cancer treated with amrubicin hydrochloride
}

\author{
YOUNG HAK KIM, TADASHI MIO, KATSUHIRO MASAGO, KAORU IRISA, \\ YUICHI SAKAMORI and MICHIAKI MISHIMA
}

Department of Respiratory Medicine, Graduate School of Medicine, Kyoto University, Kyoto 606-8507, Japan

Received January 14, 2010; Accepted March 16, 2010

DOI: $10.3892 /$ ol_00000101

\begin{abstract}
Amrubicin (AMR) is one of the most active chemotherapeutic agents for small-cell lung cancer (SCLC). Previous phase II studies reported on its effectiveness and severe hematological toxicities. However, AMR has yet to be approved outside Japan. Subsequently, no extensive evidence of its effects exist. Between January 2004 and October 2009, 69 patients received AMR for relapsed SCLC at our hospital. We reviewed these patients, and analyzed the efficacy and hematological toxicities of AMR. There were 27 sensitive relapses (S) and 42 refractory relapses $(\mathrm{R})$. Patients received platinum agents, and 43 and $71 \%$ of the patients received etoposide and irinotecan, respectively. The median number of treatment cycles was 3 (range 1-14), and the response rate was $51 \%$ (70\% in the $\mathrm{S}$ and $38 \%$ in the $\mathrm{R}$ cases, respectively). In patients administered with AMR as second-line therapy, the response rate was $55 \%$ and as third-line therapy, 39\%. Median progression-free survival time was 3.2 months in the $\mathrm{S}$ and 1.9 months in the $\mathrm{R}$ patients $(\mathrm{p}=0.1071)$. Median survival time from the start of AMR was 6.2 months in the $\mathrm{S}$ and 4.8 months in the $\mathrm{R}$ cases $(p=0.0045)$. The frequency of grade $\geq 3$ hematological toxicities was leukopenia (41\%), neutropenia (51\%), anemia (14\%), thrombocytopenia (17\%) and febrile neutropenia (12\%). No treatment-related death was observed. Although hematological toxicities, particularly neutropenia, were severe, AMR showed excellent anti-tumor activity, not only in the $S$, but also in the $\mathrm{R}$ cases, as shown in previous phase II studies. These results warrant further evaluation of AMR in the second-line setting, and also in the first-line setting in both limited- and extensivestage disease. We conducted a phase II study to assess the efficacy of consolidation chemotherapy with AMR after standard chemoradiation in limited-stage SCLC.
\end{abstract}

Correspondence to: Dr Young Hak Kim, Department of Respiratory Medicine, Graduate School of Medicine, Kyoto University, 54 Shogoin-Kawaharacho, Sakyo-ku, Kyoto 606-8507, Japan E-mail: ekim@kuhp.kyoto-u.ac.jp

Key words: small-cell lung cancer, amrubicin, relapse, sensitive, refractory

\section{Introduction}

Small-cell lung cancer (SCLC) accounts for approximately $15 \%$ of all types of lung cancer (1). Despite the high sensitivity to chemotherapy, the majority of patients develop relapse. Second-line chemotherapy is considered for cases of relapsed SCLC; however, the prognosis of such patients is usually poor. Topotecan has shown a survival benefit against best supportive care and also a comparable response rate and survival with combination chemotherapy of cyclophosphamide, doxorubicin and vincristine (CAV) in relapsed SCLC (2,3). Currently, topotecan is the only drug approved by the US Food and Drug Administration for relapsed SCLC.

Amrubicin (AMR), a totally synthetic 9-aminoanthracycline, is converted to an active metabolite, amrubicinol, by reduction of its $\mathrm{C}-13$ ketone group to a hydroxyl group (4). In a phase I/II study of patients with non-small-cell lung cancer, the recommended dose was determined to be $45 \mathrm{mg} /$ $\mathrm{m}^{2} /$ day for 3 consecutive days every 3 weeks (5). In a phase II study of SCLC, 35 patients with extensive disease (ED) were treated at the recommended dose, and a response rate of $75.8 \%$ and median survival time (MST) of 11.7 months were reported (6).

In a phase II study evaluating the activity of AMR in relapsed SCLC, the response rate and MST were 52\%, 11.6 months and 50\%, 10.3 months in sensitive and refractory relapse, respectively $(7,8)$. In addition, AMR was compared with topotecan in a randomized phase II study. In sensitive relapse $(n=36)$, response rates were $53 \%$ for AMR and $21 \%$ for topotecan, and in refractory relapse, $17 \%$ for AMR and $0 \%$ for topotecan. Overall survival (OS) was not significantly different between the two arms; however, multivariate analysis showed that AMR had more influence than topotecan on OS. Although the dose of AMR was $40 \mathrm{mg} / \mathrm{m}^{2} /$ day, lower than the recommended dose, hematological toxicity was severe in the AMR arm, and one treatment-related death resulting from infection was observed in the AMR arm (9).

AMR is one of the most active chemotherapeutic agents for SCLC. However, currently it is not approved outside Japan, and no extensive evidence of its effects exist. This study examined relapsed SCLC patients treated with AMR in our hospital and analyzed its efficacy and hematological toxicities. 
Table I. Patient characteristics.

\begin{tabular}{|c|c|c|c|}
\hline Characteristic & $\begin{array}{c}\mathrm{S} \\
(\mathrm{n}=27)\end{array}$ & $\begin{array}{c}\mathrm{R} \\
(\mathrm{n}=42)\end{array}$ & $\begin{array}{c}\text { Total } \\
(\mathrm{n}=69)\end{array}$ \\
\hline \multicolumn{4}{|l|}{ Age (years) } \\
\hline Median & 70 & 62 & 66 \\
\hline Range & $50-80$ & $33-82$ & $33-82$ \\
\hline \multicolumn{4}{|l|}{ Gender (\%) } \\
\hline Male & $23(85)$ & $32(76)$ & $55(80)$ \\
\hline Female & $4(15)$ & $10(24)$ & $14(20)$ \\
\hline \multicolumn{4}{|c|}{ Disease extent (\%) } \\
\hline LD & $10(37)$ & $5(12)$ & $15(22)$ \\
\hline ED & $17(63)$ & $37(88)$ & $54(78)$ \\
\hline \multicolumn{4}{|c|}{$\begin{array}{l}\text { Response to first-line } \\
\text { treatment }(\%)\end{array}$} \\
\hline $\mathrm{CR}$ & $8(30)$ & $5(12)$ & $13(19)$ \\
\hline PR & $19(70)$ & $28(67)$ & $47(68)$ \\
\hline SD & $0 \quad(0)$ & $5(12)$ & $5(7)$ \\
\hline PD & $0 \quad(0)$ & 4 (9) & $4(6)$ \\
\hline \multicolumn{4}{|l|}{$\begin{array}{l}\text { PS at the timing } \\
\text { of AMR }(\%)\end{array}$} \\
\hline $0-1$ & $21(78)$ & $27(64)$ & $48(70)$ \\
\hline $2-4$ & $6(22)$ & $15(36)$ & $21(30)$ \\
\hline \multicolumn{4}{|c|}{$\begin{array}{l}\text { No. of prior chemotherapy } \\
\text { regimens }(\%)\end{array}$} \\
\hline 1 & $19(70)$ & $32(76)$ & $51(74)$ \\
\hline 2 & $8(30)$ & $10(24)$ & $18(26)$ \\
\hline \multicolumn{4}{|c|}{ Previous chemotherapy (\%) } \\
\hline Platinum & $27(100)$ & $42(100)$ & $69(100)$ \\
\hline Etoposide & 13 (48) & 17 (40) & $30(43$ \\
\hline Irinotecan & 20 & $29(69)$ & $49(71$ \\
\hline Topotecan & $1 \quad(4)$ & $3(7)$ & $4 \quad(6$ \\
\hline
\end{tabular}

$\mathrm{S}$, sensitive relapse; $\mathrm{R}$, refractory relapse; $\mathrm{LD}$, limited disease; $\mathrm{ED}$, extensive disease; CR, complete response; $\mathrm{PR}$, partial response; $\mathrm{SD}$, stable disease; PD, progressive disease; PS, performance status and AMR, amrubicin.

\section{Patients and methods}

Patients. Between January 2002 and January 2009, 164 SCLC patients were admitted to Kyoto University Hospital. Among them, 112 patients received chemotherapy alone, 36 chemoradiotherapy, 6 surgical resection with adjuvant chemotherapy and 10 best supportive care. As a consequence, 92 patients received second-line chemotherapy, including 69 that received AMR. In this study, patients who responded to initial chemotherapy and relapsed $>3$ months after chemotherapy were defined as sensitive relapse (S), while patients who did not respond to initial chemotherapy or relapsed within 3 months were defined as refractory relapse $(\mathrm{R})$ patients. Patient data were obtained from our database. Consent was obtained form all patients. The study was approved by the Institutional Review Board.

Tumor evaluation and statistical analysis. Tumor response was assessed according to the Response Evaluation Criteria in Solid Tumors (10). Hematological toxicity was evaluated
Table II. Response and treatment delivery.

\begin{tabular}{lrrr}
\hline & $\mathrm{S}$ & $\mathrm{R}$ & Total \\
\hline CR & 1 & 1 & 2 \\
PR & 18 & 15 & 33 \\
SD & 5 & 8 & 13 \\
PD & 3 & 18 & 21 \\
Response rate (\%) & 70 & 38 & 51 \\
No. of treatment cycles & & & \\
Median & 4 & 2 & 3 \\
Range & $1-8$ & $1-14$ & $1-14$ \\
Dose (mg/m $/$ day) & & & \\
25 & 0 & 1 & 1 \\
30 & 6 & 11 & 17 \\
35 & 6 & 19 & 25 \\
40 & 9 & 8 & 17 \\
45 & 6 & 3 & 9 \\
\hline
\end{tabular}

$\mathrm{S}$, sensitive relapse; $\mathrm{R}$, refractory relapse; $\mathrm{CR}$, complete response; $\mathrm{PR}$, partial response; $\mathrm{SD}$, stable disease and $\mathrm{PD}$, progressive disease.

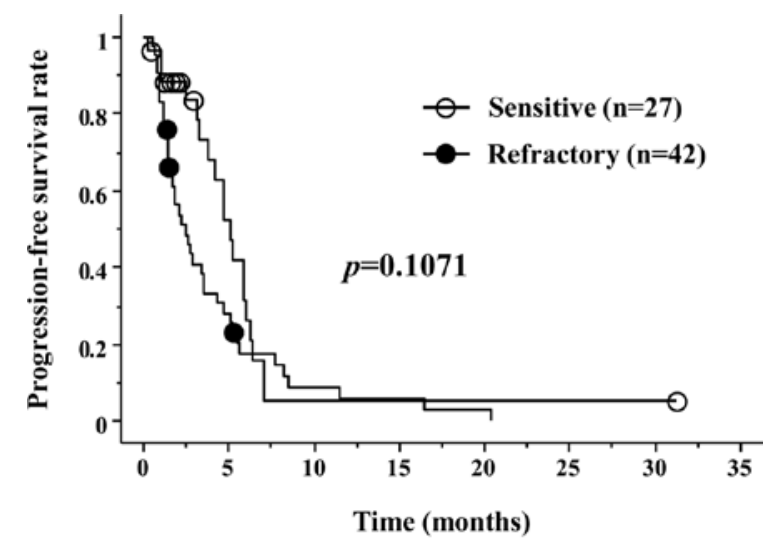

Figure 1. Progression-free survival (PFS) of sensitive and refractory relapse patients. Median PFS was 3.2 months in the sensitive group and 1.9 months in the refractory group, respectively $(\mathrm{p}=0.1071)$.

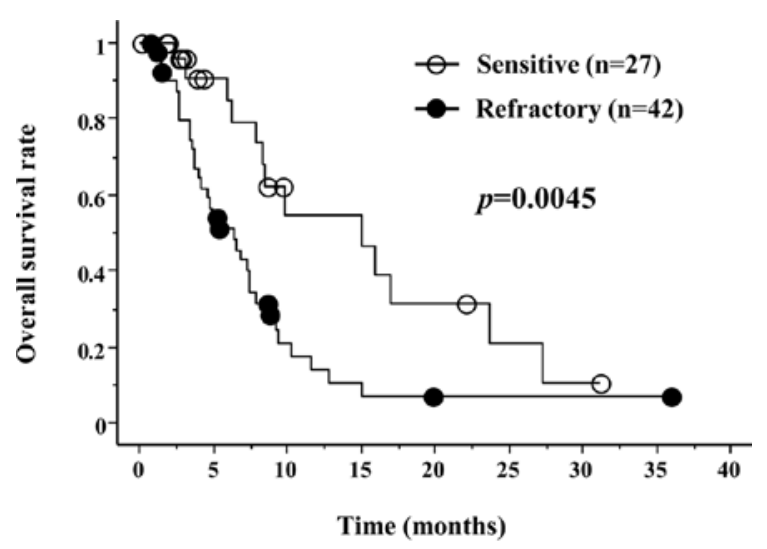

Figure 2. Overall survival (OS) of sensitive and refractory relapse patients. Median OS was 6.2 months in the sensitive group and 4.8 months in the refractory group, respectively $(\mathrm{p}=0.0045)$. 
Table III. Univariate and multivariate analyses for overall survival.

\begin{tabular}{|c|c|c|c|c|c|}
\hline \multirow[t]{2}{*}{ Variables } & \multirow[t]{2}{*}{ MST (months) } & \multirow{2}{*}{$\frac{\text { Univariate }}{\text { p-value }}$} & \multicolumn{3}{|c|}{ Multivariate } \\
\hline & & & Risk ratio & $95 \% \mathrm{CI}$ & $\mathrm{p}$-value \\
\hline \multicolumn{6}{|l|}{ Age } \\
\hline$<70$ & 5.3 & 0.9299 & 0.544 & $0.277-1.069$ & 0.0775 \\
\hline$\geq 70$ & 4.9 & & & & \\
\hline \multicolumn{6}{|l|}{ Gender } \\
\hline Male & 5.4 & 0.3841 & 2.148 & $0.942-4.901$ & 0.0691 \\
\hline Female & 5.0 & & & & \\
\hline \multicolumn{6}{|l|}{ PS } \\
\hline $0-1$ & 6.4 & 0.0039 & 0.388 & $0.197-0.763$ & 0.0060 \\
\hline $2-4$ & 2.5 & & & & \\
\hline \multicolumn{6}{|c|}{ Relapse pattern } \\
\hline Sensitive & 6.2 & 0.0045 & 3.533 & $1.656-7.540$ & 0.0011 \\
\hline Refractory & 4.8 & & & & \\
\hline
\end{tabular}

MST, median survival time; CI, confidence interval and PS, performance status.

Table IV. Hematological toxicities.

\begin{tabular}{lcccrr}
\hline Event & Grade 1 & Grade 2 & Grade 3 & Grade 4 & $\geq$ Grade 3 $(\%)$ \\
\hline Leukopenia & 12 & 16 & 18 & 10 & $28(41)$ \\
Neutropenia & 10 & 18 & 17 & 6 & $35(51)$ \\
Anemia & 19 & 32 & 8 & 4 & $10(14)$ \\
Thrombocytopenia & 18 & 8 & 8 & 4 & 0 \\
Febrile neutropenia & 0 & 0 & $(17)$ & $8(12)$ \\
\hline
\end{tabular}

according to the Common Terminology Criteria for Adverse Events (CTCAE v3.0). Survival time was measured from the start of chemotherapy to either the time of the patient succumbing to the disease due to any cause or the date when patients were last known to be alive. The survival curve was estimated using the Kaplan-Meier method and compared using the log-rank test. Individual clinical factors were compared using the $\chi^{2}$ test. Multivariate analysis was conducted according to the Cox proportional hazards model. $\mathrm{P}<0.05$ was considered to be significant. Statistical analyses were performed using StatView, version 5.0 (Abacus Concepts, Berkeley, CA, USA).

\section{Results}

Patient characteristics. Patient characteristics are listed in Table I. There were $27 \mathrm{~S}$ and $42 \mathrm{R}$ cases. The median age was 70 years for sensitive patients and 62 for refractory patients. Most patients $(\sim 80 \%)$ were male in the two groups. The proportion of ED cases was $63 \%$ in sensitive patients and $88 \%$ in refractory patients. The proportion of performance status (PS) 2-4 was higher in the R group. Patients had previously received platinum agents, and $\sim 40$ and $70 \%$ had received etoposide and irinotecan, respectively. AMR as second-line treatment was received by $74 \%$ of patients and as third-line treatment by the remaining patients.

Response and treatment delivery. Table II shows results of the response and treatment delivery. There were 1 complete response (CR), 18 partial response (PR), 5 stable disease (SD) and 3 progressive disease (PD) cases in the $S$ group (response rate $70 \%$ ) and $1 \mathrm{CR}, 15 \mathrm{PR}, 8 \mathrm{SD}$ and $18 \mathrm{PD}$ cases in the $\mathrm{R}$ group (response rate $38 \%$ ). The median number of treatment cycles was 4 (range 1-8) in the $S$ group and 2 (range 1-14) in the $\mathrm{R}$ group. The median dose of AMR was $40 \mathrm{mg} / \mathrm{m}^{2}$ in the $\mathrm{S}$ group and $35 \mathrm{mg} / \mathrm{m}^{2}$ in the $\mathrm{R}$ group, respectively.

Survival. Progression-free survival (PFS) is shown in Fig. 1. Median PFS was 3.2 months in the $\mathrm{S}$ group and 1.9 months in the $\mathrm{R}$ group, respectively ( $\mathrm{p}=0.1071)$. OS was significantly better in the $\mathrm{S}$ group (Fig. 2). Median OS was 6.2 months in the $\mathrm{S}$ group and 4.8 months in the $\mathrm{R}$ group, respectively $(\mathrm{p}=0.0045)$. Univariate and multivariate analyses showed that PS of 0-1 or 2-4 for AMR, and the relapse pattern (sensitive or refractory) were both independent prognostic factors for OS (Table III).

Hematological toxicities. Results of the hematological toxicities are listed in Table IV. The frequency of grade $\geq 3$ 
hematological toxicities was leukopenia (41\%), neutropenia (51\%), anemia (14\%), thrombocytopenia (17\%) and febrile neutropenia $(12 \%)$. The number of patients requiring the administration of granulocyte-stimulating factor (G-CSF), red blood cell transfusion and platelet transfusion were $34(50 \%)$, $7(10 \%)$ and $2(3 \%)$, respectively. No treatment-related death was noted.

\section{Discussion}

SCLC is highly sensitive to chemotherapy. Therefore, the main treatment strategy for SCLC is systemic chemotherapy. Currently, both cisplatin + etoposide and cisplatin + irinotecan are considered to be standard chemotherapeutic regimens for SCLC (11). Despite the high initial sensitivity to chemotherapy, the majority of patients develop relapse, and the prognosis of patients with relapsed SCLC is usually poor. The effects of topotecan, a DNA topoisomerase-I inhibitor, are extensively evaluated in patients with relapsed SCLC. Currently, topotecan is the only drug approved by the US Food and Drug Administration for relapsed SCLC. AMR has shown promising anti-tumor activity in previous phase II studies for relapsed SCLC, as well as superiority in a randomized phase II study compared to topotecan (7-9). AMR is at present being examined for SCLC worldwide. However, it has yet to be approved outside Japan. Therefore, clinical data regarding AMR is limited.

In a randomized phase II study comparing AMR with topotecan, the response rate in the AMR arm was better in $\mathrm{S}$ with $53 \%$ in $\mathrm{S}$ and $17 \%$ in $\mathrm{R}$ cases, respectively (9). However, in previous single-arm phase II studies of AMR, a comparable response rate was noted between $\mathrm{S}$ and $\mathrm{R}$ cases [52 and 50\% in Onoda et al (7); 40 and 50\% in Kato et al (8)]. Considering that $\mathrm{R}$ is extremely chemo-resistant, the anti-tumor activity of AMR is considerably promising. Although inferior to $\mathrm{S}$, a response rate of $38 \%$ was observed in the $\mathrm{R}$ group in our study.

PFS was not significantly different between $S$ and $\mathrm{R}$ patients. However, OS was significantly more favorable in the $\mathrm{S}$ patients (6.2 vs. 4.8 months, $\mathrm{p}=0.0045)$. Multivariate analysis demonstrated that PS of $0-1$ or $2-4$ for AMR, and the relapse pattern (sensitive or refractory) were both independent prognostic factors for OS. The results were consistent with our previous study (12).

Hematological toxicities, particularly neutropenia, were found to be severe, as shown in previous studies. Although the majority of patients received AMR under the recommended dose, $50 \%$ required G-CSF support in our study. In previous single-arm phase II studies of AMR, the frequency of grade $\geq 3$ neutropenia and G-CSF support were 83.3 and $70 \%$, respectively, at a dose of $40 \mathrm{mg} / \mathrm{m}^{2}$, and 97 and $71 \%$, respectively, at a dose of $45 \mathrm{mg} / \mathrm{m}^{2}(7,8)$. Since the recommended dose of $45 \mathrm{mg} / \mathrm{m}^{2}$ was determined in chemo-naïve patients, it may be too high for previously treated patients. Igawa et al evaluated the recommended dose of AMR in previously treated SCLC patients and determined the dose to be $40 \mathrm{mg} / \mathrm{m}^{2}$ for secondline and $35 \mathrm{mg} / \mathrm{m}^{2}$ for third-line treatment (13).

In conclusion, in this retrospective study, we confirmed that AMR has excellent anti-tumor activity, not only in sensitive relapse, but also in refractory relapse, as shown in previous phase II studies. These results warrant further evaluation of AMR in both the second and first-line setting in limitedand extensive-stage disease. We are currently conducting a phase II study to assess the efficacy of consolidation chemotherapy following AMR following standard chemoradiation in limited-stage SCLC.

\section{References}

1. Jackman DM and Johnson BE: Small-cell lung cancer. Lancet 366: 1385-1396, 2005.

2. O'Brien ME, Ciuleanu TE, Tsekov H, et al: Phase III trial comparing supportive care alone with supportive care with oral topotecan in patients with relapsed small-cell lung cancer. J Clin Oncol 24: 5441-5447, 2006.

3. Von Pawel J, Schiller JH, Shepherd FA, et al: Topotecan versus cyclophosphamide, doxorubicin and vincristine for the treatment of recurrent small-cell lung cancer. J Clin Oncol 17: 658-667, 1999.

4. Inoue K, Ogawa M, Horikoshi N, et al: Phase I and pharmacokinetic study of SM-5887, a new anthracycline derivative. Invest New Drugs 7: 213-218, 1989.

5. Negoro S, Fukuoka M, Nakamura S, et al: Phase I-II study of amrubicin (SM-5887), a novel 9-aminoanthracycline, by iv administration for 3 consecutive days in patients with advanced non-small cell lung cancer. Proc Am Soc Clin Oncol 14: 361, 1995.

6. Yana T, Negoro S, Takada M, et al: Phase II study of amrubicin in previously untreated patients with extensive-disease small cell lung cancer: West Japan Thoracic Oncology Group (WJTOG) study. Invest New Drugs 25: 253-258, 2007.

7. Onoda S, Masuda N, Seto T, et al: Phase II trial of amrubicin for treatment of refractory or relapsed small-cell lung cancer: Thoracic Oncology Research Group Study 0301. J Clin Oncol 24: 5448-5453, 2006.

8. Kato T, Nokihara H, Ohe Y, et al: Phase II trial of amrubicin in patients with previously treated small cell lung cancer (SCLC). Proc Am Soc Clin Oncol 24: 7061, 2006.

9. Inoue A, Sugawara S, Yamazaki K, et al: Randomized phase II trial comparing amrubicin with topotecan in patients with previously treated small-cell lung cancer: North Japan Lung Cancer Study Group Trial 0402. J Clin Oncol 26: 5401-5406, 2008.

10. Therasse P, Arbuck SG, Eisenhauer EA, et al: New guidelines to evaluate the response to treatment in solid tumors. European Organization for Research and Treatment of Cancer, National Cancer Institute of the United States, National Cancer Institute of Canada. J Natl Cancer Inst 92: 205-216, 2000.

11. Simon GR and Turrisi A: Management of small cell lung cancer: ACCP evidence-based clinical practice guidelines (2nd edition). Chest 132: S324-S339, 2007.

12. Kim YH, Goto K, Yoh K, et al: Performance status and sensitivity to first-line chemotherapy are significant prognostic factors in patients with recurrent small cell lung cancer receiving second-line chemotherapy. Cancer 113: 2518-2523, 2008.

13. Igawa S, Yamamoto N, Ueda S, et al: Evaluation of the recommended dose and efficacy of amrubicin as second- and third-line chemotherapy for small cell lung cancer. J Thorac Oncol 2: 741-744, 2007. 